\title{
THỰC TRẠNG BÊNH ĐÁI THÁO ĐƯờNG Ở NGƯờI TÙ 25 TUỔI TRỞ LÊN TRÊN ĐỊA BÀN TỈNH VĨNH PHÚC NĂM 2018
}

Nguyễn Hoài Lê

TT Kiểm soát bệnh tật Vĩnh Phúc

DOI: $10.47122 / v j d e .2020 .41 .13$

Chịu trách nhiệm chính: Nguyễn Hoài Lê

Ngày nhận bài: 4/8/2020

Ngày phản biện khoa học: 8/9/2020

Ngày duyệt bài: 10/10/2020

Email: lenguyenhoai@gmail.com

\section{1. ĐẠT VẤN ĐỀ}

Việt Nam là một nước đang phát triển nằm trong khu vực Tây Thái Bình Dương, khu vực đang có những thay đổi lớn không chỉ về kinh tế mà cả về môi trường và mô hình bệnh tật. Cùng với các bệnh không lây nhiễm khác, bệnh đái tháo đường ( $\mathrm{ÐTÐ)} \mathrm{đang} \mathrm{phát} \mathrm{triển}$ với tốc độ nhanh. Theo Tổ chức Y tế thế giới (WHO), năm 1980 có khoảng 108 triệu người mắc ĐTĐ trên toàn cầu và đến năm 2014 con số này ước tính tăng gấp 4 lần. Liên đoàn Đái tháo đường Quốc tế (IDF) ước tính tỷ lệ lưu hành toàn cầu của bệnh ĐTĐ năm 2000 là 151 triệu người, năm 2009 là 366 triệu người và năm 2015 là 415 triệu người mắc bệnh ĐТÐ [1].

Vĩnh Phúc là một tỉnh thuộc vùng quy hoạch Thủ đô, vùng kinh tế trọng điểm đồng bằng Bắc bộ, có hệ thống giao thông thuận lợi, là cầu nối giữa vùng trung du miền núi phía Bắc với Thủ đô Hà Nội. Trong những năm qua, cùng với sự phát triển kinh tế - xã hội nói chung thì những nguy cơ về bệnh tật, đáng chú ý là các bệnh không lây nhiềm trong đó có ĐTĐ cũng tăng nhanh.

Nhằm xác định thực trạng của bệnh Đái tháo đường trên địa bàn tỉnh Vĩnh Phúc, làm cơ sở để xây dựng các kế hoạch phù hợp phòng chống bệnh Đái tháo đường cho người dân trên địa bàn tỉnh, chúng tôi tiến hành nghiên cứu đề tài “Thục trạng bệnh Đái tháo đường và một số yếu tố nguy cơ ở người tù̀ 25 tuổi trở lên trên địa bàn tỉnh Vĩnh Phúc năm 2018" với mục tiêu cụ thể là: Mô tả thực trạng bệnh Đái tháo đường và một số yếu tố nguy co liên quan ở người tù 25 tuổi trở lên tại tỉnh Vinh Phúc năm 2018.

\section{2. ĐỐI TỰ̛̣G VÀ PHƯƠNG PHÁP NGHIÊN CÚ'U}

2.1. Thiết kế nghiên cứu: Phương pháp nghiên cứu mô tả, thiết kế nghiên cứu cắt ngang.

2.2. Đối tượng điều tra: Người dân từ 25 tuổi trở lên.

Tiêu chuẩn lựa chọn: Người đang sinh sống tại xã được điều tra, đối tượng tự nguyện đồng ý tham gia nghiên cứu.

Tiêu chuẩn loại trừ: người không có khả năng trả lời phỏng vấn (người khuyết tật câm, điếc, tâm thần...)

2.3. Thời gian điều tra: Từ tháng 8 đến tháng 10 năm 2018.

2.4. Địa điểm điều tra: Tiến hành tại 36 xã trên 9 huyện thị của tỉnh Vĩnh Phúc.

2.5. Cõ̃ mẫu và phương pháp chọn mẫu

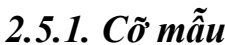

Áp dụng cỡ mẫu điều tra cho nghiên cứu mô tả cắt ngang:

Trong đó:

$$
n=\frac{Z_{1-\alpha / 2}^{2} p(1-p)}{d^{2}} \times \mathrm{DE}
$$

$+\mathrm{n}$ : cỡ mẫu tối thiểu cho nghiên cứu.

+ Với $\mathrm{p}$ là tỷ lệ bệnh ĐTĐ ở người trưởng thành theo IDF năm 2015 là $8,8 \%$

$+\mathrm{d}$ là độ chính xác tuyệt đối lấy bằng 0,05 .

$+Z_{1-\alpha / 2}$ là hệ số tin cậy, bằng 1,96 với độ tin cậy $99 \%$.

+ DE là hệ số thiết kế, ta lấy bằng 23,3

Ta tính được $\mathrm{n}=2873$, làm tròn số ta sẽ chọn 2880 đối tượng điều tra.

\subsubsection{Phương pháp chọn mẫu nghiên} cúu

- Tại mỗi huyện chọn ngẫu nhiên 4 xã, 9 huyện là 36 xã. 
- Tại mỗi xã lập danh sách tất cả các thôn hoặc khu hành chính của xã, sau đó bắt thăm chọn ngẫu nhiên 2 thôn hoặc khu hành chính để điều tra nghiên cứu.

- Tại mỗi thôn hoặc khu hành chính lập danh sách tất cả các đối tượng nam và nữ từ 25 tuổi trở lên. Chọn theo phương pháp tính khoảng cách mẫu $\mathrm{k}$ tại các danh sách đối tượng. Mỗi thôn chọn 40 đối tượng điều tra.

- Lên danh sách đối tượng điều tra, y tế thôn bản giải thích về cuộc điều tra và phát giấy mời đối tượng tham gia, hướng dẫn đối tượng không ăn sau 9 giờ tối hôm trước điều tra.

\subsection{Tiêu chuẩn chẩn đoán}

\subsubsection{Chẩn đoán ĐTÐ và tiền ĐTÐ}

Chẩn đoán ĐTĐ và tiền ĐTĐ theo quy định của Bộ Y tế [2].

- Chẩn đoán ĐTĐ:

+ Glucose lúc đói $\geq 7,0 \mathrm{mml} / 1$

+ Glucose giờ thứ 2 sau làm nghiệm pháp tăng đường huyết $\geq 11,1$

+ Mức glucose ở thời điểm bất kỳ $\geq 11,1$ $\mathrm{mmol} / \mathrm{l}$

- Chẩn đoán tiền ĐTĐ:

+ Rối loạn dung nạp glucose nếu mức glucose ở thời điểm 2 giờ sau nghiệm pháp tăng glucose máu bằng đường uống từ 7,8 $\mathrm{mmol} / \mathrm{l}$ đến $11,0 \mathrm{mmol} / \mathrm{l}$

+ Suy giảm glucose máu lúc đói nếu lượng glucose lúc đói (sau ăn 8 giờ) từ $6,1 \mathrm{mmol} / 1$ đến $6,9 \mathrm{mmol} / 1$ và lượng glucose ở thời điểm 2 giờ của nghiệm pháp tăng glucose máu dưới $7,8 \mathrm{mmol} / \mathrm{l}$

\subsubsection{Chẩn đoán thù̀a cân béo phì}

Đánh giá tình trạng thừa cân, béo phì theo khuyến cáo của WHO khu vực Tây Thái Bình Dương năm 2000 cho người trưởng thành châu Á theo BMI. Chẩn đoán thừa cân khi
$\mathrm{BMI} \geq 23$; béo phì khi $\mathrm{BMI} \geq 25$ [3].

\subsubsection{Chẩn đoán béo bụng}

Theo Tổ chức Y tế thế giới khu vực châu Á Thái Bình Dương béo phì vùng bụng được định nghĩa khi tỉ số vòng bụng/vòng mông (WHR) $\geq 0,9$ ở nam và $\geq 0,8$ ở nữ [4].

\subsubsection{Uống rươu bia nhiều}

Theo hướng dẫ் của Bộ $\mathrm{Y}$ tế, được coi là uống nhiều rượu bia là nam giới uống quá 3 cốc chuẩn/ngày, nữ giới uống quá 2 cốc chuẩn/ngày (một cốc chuẩn chứa $10 \mathrm{~g}$ ethanol tương đương $330 \mathrm{ml}$ bia hoặc $120 \mathrm{ml}$ rượu vang hoặc 30ml rượu mạnh) [2].

\subsubsection{Tiền sử gia đình}

Trong gia đình (bố, mẹ, anh chị em ruột) có người mắc bệnh ĐTĐ.

\subsection{Kỹ thuật áp dụng trong nghiên cứu}

- Phỏng vấn trực tiếp để thu thập các số liệu về năm sinh, giới tính, tiền sử gia đình...theo bộ phiếu chuẩn bị sẵn.

- Cân đo: đo chiều cao, cân nặng, vòng eo, vòng hông.

- Xét nghiệm glucose lúc đói: Lấy máu mao mạch, xét nghiệm nhanh đường huyết bằng máy Accu-Chek- D10-BIO-RAD tại trạm y tế các xã. Trước khi tiến hành điều tra, máy đã được kiểm tra độ chính xác.

- Làm nghiệm pháp dung nạp đường huyết cho những đối tượng có rối loạn glucose máu lúc đói. Sau 2 giờ xét nghiệm lại lần 2 .

- Xử lý và phân tích số liệu nghiên cứu: Nhập dữ liệu trên phần mềm EPI DATA 3.1, Phân tích và xử lý số liệu sử dụng phần mềm SPSS 16.0.

Dùng test Khi bình phương $(\chi 2)$ để kiểm định sự khác biệt thống kê.

\section{KẾT QUẢ NGHIÊN CÚU}

\subsection{Thông tin chung về đối tượng nghiên cứu}

Bảng 3.1. Thông tin chung về đối tượng nghiên cứu

\begin{tabular}{|l|l|c|c|}
\hline \multicolumn{2}{|l|}{ Thông tin } & Số lượng & Tỷ lệ \% \\
\hline \multirow{2}{*}{ Giới tính: } & Nam & 1078 & 37,4 \\
\cline { 2 - 4 } & Nữ & 1802 & 62,6 \\
\hline
\end{tabular}




\begin{tabular}{|l|l|c|c|}
\hline \multirow{3}{*}{ Độ tuổi: } & 25 đến 39 tuổi & 560 & 19,4 \\
\cline { 2 - 4 } & 40 đến 59 tuổi & 1090 & 37,8 \\
\cline { 2 - 4 } & 60 đến 79 tuối & 955 & 33,2 \\
\cline { 2 - 4 } & $\geq 80$ tuối & 275 & 9,6 \\
\hline \multicolumn{2}{|c|}{ Cộng } & $\mathbf{2 8 8 0}$ & $\mathbf{1 0 0}$ \\
\hline
\end{tabular}

* Nhận xét: Tỷ lệ đối tượng nam, nữ được điều tra là chênh lệch đáng kể (nam: 37,4\%, nữ: $62,6 \%)$. Phân bố độ tuổi cũng chênh lệch đáng kể đặc biệt là độ tuổi từ 80 tuổi trở lên có rất ít người tham gia $(9,6 \%)$.

3.2. Tình trạng bệnh đái tháo đường

\title{
3.2.1. Ty lệ bệnh đái tháo đuờng
}

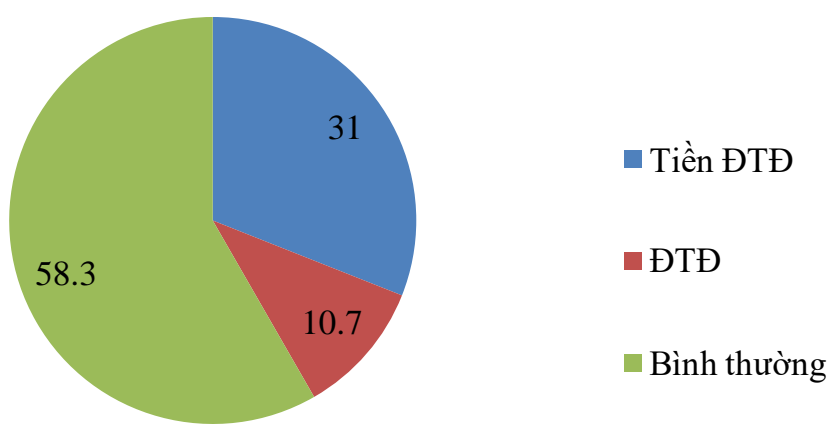

Biểu đồ 3.1. Tỷ lệ bệnh đái tháo đường

* Nhận xét: Qua điều tra phát hiện số người tiền đái tháo đường là 892 người chiếm tỷ lệ $31,0 \%$. Tỷ lệ mắc bệnh đái tháo đường là 10,7\% (307 người).

\subsubsection{Tỷ lệ người bệnh đái tháo đường đã đự̣c phát hiện}

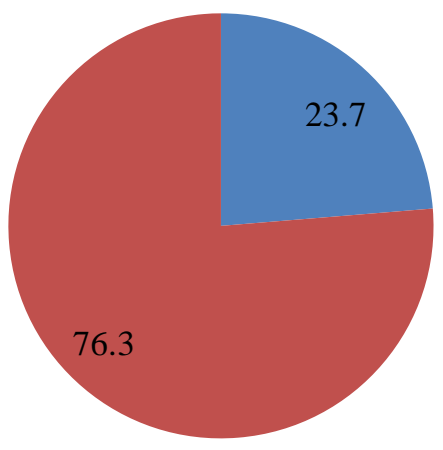

\author{
— Được phát hiện ĐTĐ \\ trước khi điều tra \\ - Mới được phát hiện \\ ĐTĐ khi điều tra
}

Biểu đồ 3.2. Tỷ lệ người bệnh đái tháo đường đã được phát hiện

* Nhận xét:

Qua điều tra phát hiện số người đã được phát hiện mắc bệnh đái tháo đường chỉ chiếm $23,7 \%$. Tỷ lệ người mắc bệnh ĐTĐ mà không biết mình bị mắc bệnh còn rất cao $(76,3 \%)$. 
3.3. Liên quan đến mắc bệnh đái tháo đường với một số yếu tố nguy cơ

Bảng 3.1. Tỷ lệ mắc bệnh ĐTĐ theo lứa tuổi

\begin{tabular}{|c|c|c|}
\hline Lứa tuổi & Số mắc ĐTÐ & Tỷ lệ \% \\
\hline $25-39$ & 21 & 6,8 \\
\hline $40-59$ & 113 & 36,8 \\
\hline $60-79$ & 129 & 42,0 \\
\hline$\geq 80$ & 44 & 14,4 \\
\hline Tống số & $\mathbf{3 0 7}$ & $\mathbf{1 0 0}$ \\
\hline
\end{tabular}

* Nhận xét: Tỷ lệ mắc bệnh đái tháo đường ở độ tuối 60 - 79 tuối là cao nhất: 42,0\%. Thấp nhất là ở độ tuổi từ $25-39: 6,8 \%$.

Bảng 3.2. Liên quan mắc đái tháo đường với một số yếu tố nguy cơ

\begin{tabular}{|c|c|c|c|c|c|c|}
\hline Yếu tố nguy co' & ĐТÐ & $\begin{array}{c}\text { Không } \\
\text { ĐTÐ }\end{array}$ & $\begin{array}{l}\text { Tỷ lệ \% } \\
\text { YTNC }\end{array}$ & $\mathbf{P}$ & OR & $95 \% \mathrm{CI}$ \\
\hline Giới & & & & \multirow{4}{*}{0,000} & \multirow{4}{*}{1,573} & \multirow{4}{*}{$1,240-1,996$} \\
\hline $\operatorname{Nam}(1078)$ & 145 & 933 & & & & \\
\hline Nữ (1802) & 162 & 1640 & & & & \\
\hline Tổng số (2880) & 307 & 2573 & & & & \\
\hline \multicolumn{4}{|l|}{ Tuổi } & \multirow{4}{*}{0,000} & \multirow{4}{*}{3,812} & \multirow{4}{*}{$2,399-6,057$} \\
\hline$\leq 40$ tuổi $(2320)$ & 287 & 2033 & & & & \\
\hline$>40$ tuồi $(560)$ & 20 & 540 & & & & \\
\hline Tổng số (2880) & 307 & 2573 & & & & \\
\hline Hút thuốc lá & & & 12 & \multirow{4}{*}{0,138} & \multirow{4}{*}{1,292} & \multirow{4}{*}{$0,921-1,812$} \\
\hline Có hút thuốc lá (347) & 45 & 302 & & & & \\
\hline Không hút thuốc lá (2533) & 262 & 2271 & & & & \\
\hline Tổng số (2880) & 307 & 2573 & & & & \\
\hline Uống nhiều rượu & & & 7,7 & \multirow{4}{*}{0,017} & \multirow{4}{*}{1,632} & \multirow{4}{*}{$1,114-2,392$} \\
\hline Uống nhiều rượu (223) & 35 & 188 & & & & \\
\hline Không uống nhiều rượu (2657) & 272 & 2385 & & & & \\
\hline Tổng số (2880) & 307 & 2573 & & & & \\
\hline Thừa cân béo phì & & & 31,4 & \multirow{4}{*}{0,000} & \multirow{4}{*}{1,756} & \multirow{4}{*}{$1,380-2,235$} \\
\hline Có thừa cân béo phì (905) & 132 & 773 & & & & \\
\hline Không thừa cân béo phì (1975) & 175 & 1800 & & & & \\
\hline Tổng số (2880) & 307 & 2573 & & & & \\
\hline Tiền sử gia đình ĐTĐ & & & 5,4 & \multirow{4}{*}{0,061} & \multirow{4}{*}{1,568} & \multirow{4}{*}{$0,998-2,464$} \\
\hline Có tiền sử gia đình (156) & 24 & 132 & & & & \\
\hline Không có tiền sử gia đình (2724) & 283 & 2441 & & & & \\
\hline Tổng số (2880) & 307 & 2573 & & & & \\
\hline WHR của Nam cao & & & 49,3 & \multirow{4}{*}{0,247} & \multirow{4}{*}{1,234} & \multirow{4}{*}{$0,869-1,752$} \\
\hline WHR $\geq 0,9(531)$ & 78 & 453 & & & & \\
\hline WHR $<0,9(547$ & 67 & 480 & & & & \\
\hline Tổng số (1078) & 145 & 933 & & & & \\
\hline WHR của Nữ cao & & & 87,8 & \multirow{2}{*}{0,000} & \multirow{2}{*}{3,902} & \multirow{2}{*}{$1,705-8,930$} \\
\hline WHR $\geq 0,8(1582)$ & 156 & 1426 & & & & \\
\hline
\end{tabular}




\begin{tabular}{|c|c|c|c|c|c|c|}
\hline WHR $<0,8$ (220) & 6 & 214 & & & & \\
\cline { 1 - 3 } Tống số (1802) & 162 & 1640 & & & & \\
\hline
\end{tabular}

- Nhận xét: Có mối liên quan có ý nghĩa thống kê giữa mắc bệnh ĐTĐ và tuổi $(\geq 40$ tuổi), giới, uống nhiều rượu, thừa cân béo phì, WHR cao ở nữ với $\mathrm{p}<0,05$, cụ thể là:

+ Người $\geq 40$ tuổi có nguy cơ mắc bệnh ĐTĐ gấp 3,812 lần người dưới 40 tuổi.

+ Nam có nguy cơ mắc bệnh ĐTĐ gấp 1,573 lần nữ giới.

+ Người uống nhiều rượu có nguy cơ mắc bệnh ĐTĐ gấp 1,632 lần người không uống nhiều rượu.

+ Người thừa cân béo phì có nguy cơ mắc bệnh ĐTĐ gấp 1,756 lần người không bị thừa cân béo phì.

Không tìm thấy mối liên quan giữa mắc bệnh ĐTĐ với việc hút thuốc lá hay tiền sử gia đình có người mắc bệnh ĐTĐ.

\section{BÀN LUẬn \\ 4.1. Thông tin chung về đối tượng nghiên cứu}

Trong nghiên cứu, nữ (chiếm 62,6\%) nhiều hơn nam $(37,4 \%)$, điều này cũng phù hợp với cơ cấu dân số của tỉnh là nữ nhiều hơn nam, tính chung các độ tuổi thì nữ chiếm $50,55 \%$ cơ cấu dân số, nam chiếm $49,45 \%$. Trong nghiên cứu chỉ điều tra người từ 25 tuổi trở lên nên tỷ lệ nữ được điều tra cũng cao hơn nam là phù hợp [5].

Lứa tuổi chủ yếu được điều tra từ 40 đến 79 tuổi (chiếm 71\%). Điều này là phù hợp thực tế vì từ 40 đến 79 tuổi có khoảng cách tuổi là 39 năm nên sẽ đông người được điều tra hơn lứa tuổi từ 25 đến 39 (khoảng cách tuổi là 14 năm), lứa tuổi từ 80 trở lên cũng ít trong điều tra là phù hợp vì tuổi thọ trung bình của người dân Vĩnh Phúc năm 2017 là 74,1 tuổi, trong đó nam là 71,6 tuổi; nữ là 76,8 tuổi\% [5].

\subsection{Tình trạng bệnh đái tháo đường}

Kết quả điều tra 2880 người tại 36 xã trên địa bàn Vĩnh Phúc với độ tuổi từ 25 trở lên đã phát hiện tỷ lệ mắc bệnh đái tháo đường là $10,7 \%$ và tỷ lệ tiền đái tháo đường là $31 \%$. Tỷ lệ mắc ĐTĐ cao hơn điều tra của Hoàng Đức
Hạnh, Chu Thị Thu Hà, Bùi Công Đức của Hà Nội năm 2014 ở người từ 30 - 69 tuổi là $7,9 \%$ [6] và cao hơn so với điều tra của Vũ Đình Triển, Đặng Bích Thủy tại Thái Bình ở người từ 25 tuổi trở lên là $6,5 \%$ [7]. Ở nghiên cứu này, chúng tôi thấy tỷ lệ ĐTĐ, tiền ĐTĐ đều cao hơn so với điều tra Quốc gia năm 2012 khi tỉ lệ ĐTĐ chung toàn quốc là $5,42 \%$ và tiền ĐTĐ là $13,68 \%$ [8]. Tỷ lệ mắc bệnh phản ảnh khá rõ sự liên quan về tốc độ phát triển kinh tế và đời sống của người dân các vùng kinh tế khác nhau.Tại Vĩnh phúc có sự phát triển nhanh về kinh tế trong 10 năm trở lại đây tuy nhiên người dân vẫn chưa biết nhiều về phòng chống bệnh ĐTĐ dẫn đến tỷ lệ bệnh cao hơn địa phương khác.

Tỷ lệ mắc tiền ĐTĐ là $31 \%$ cũng rất đáng báo động. Nếu không can thiệp kịp thời số mắc tiền ĐTĐ sẽ nhanh chóng chuyển sang tiến triển thành bệnh ĐTĐ, trở thành gánh nặng $\mathrm{y}$ tế và kinh tế cho người dân và cộng đồng.Nghiên cứu cũng chỉ ra một thực trạng đáng quan tâm là tỷ lệ người bệnh mắc ĐTĐ trong cộng đồng không được phát hiện là $76,3 \%$, cao hơn so với kết quả điều tra toàn quốc năm 2012 là 63,8\% [8]. Trên thế giới thì cứ một bệnh nhân ĐTĐ được quản lý điều trị thì sẽ có một bệnh nhân mắc ĐTĐ trong cộng đồng không được chẩn đoán (50:50), điều này đặt ra vấn đề cho Dự án phòng, chống bệnh ĐTĐ là cần đầu tư nguồn lực nhiều hơn nữa cho việc sàng lọc, phát hiện sớm bệnh ĐTĐ trong cộng đồng và nâng cao hiệu quả công tác quản lý, điều trị cho người bệnh ĐTĐ.

\subsection{Liên quan đến mắc bệnh đái tháo đường với một số yếu tố nguy cơ}

- Nghiên cứu cho thấy tỷ lệ mắc bệnh ĐTĐ cao nhất ở lứa tuổi 40 - 79, thấp nhất ở lứa tuổi $25-39$, điều này phù hợp với các nghiên cứu khác trong nước cũng như trên thế giới; trong đó, tuổi là yếu tố nguy cơ không thể thay đổi được. Hiện nay tuổi thọ ngày càng gia tăng đặc biệt ở các nước đang phát triển khi điều kiện dinh dưỡng được cải thiện, điều kiện vệ sinh tốt hơn, các bệnh lý nhiểm 
khuẩn được khống chế và có nhiều phương thức điều trị mới được áp dụng thì bệnh ĐTĐ đang ngày càng gia tăng. Trong nghiên cứu của chúng tôi, người từ 40 tuổi trở lên có nguy cơ mắc bệnh ĐTĐ gấp 3,812 lần người dưới 40 tuổi $(\mathrm{p}<0,05)$.

- Nam giới có nguy cơ mắc bệnh ĐTĐ cao hơn nữ giới 1,573 lần, sự khác biệt có ý nghĩa thống kê và cũng phù hợp với nghiên cứu của một số tác giả khác trong nước như của Hoàng Đức Hạnh, Chu Thị Thu Hà, Bùi Công Đức của Hà Nội năm 2014 [6], Vũ Đình Triển, Đặng Bích Thủy tại Thái Bình năm 2017 [7]. Điều này có thể giải thích bởi các yếu tố nguy cơ hành vi giữa nam và nữ. Trong nghiên cứu cũng chỉ ra người uống nhiều rượu có nguy cơ mắc bệnh ĐTĐ gấp 1,632 lần người uống ít hoặc không uống rượu $(\mathrm{p}<0,05)$.

- Nghiên cứu của chúng tôi cho thấy tỷ lệ người dân Vĩnh Phúc thừa cân béo phì ở mức cao: $31,4 \%$. Đây là một yếu tố nguy cơ rất có hại cho sức khỏe. Kết quả cũng cho thấy người thừa cân béo phì có nguy cơ mắc bệnh ĐTĐ cao gấp 1,756 lần người không bị thừa cân béo phì $(\mathrm{p}<0,05)$. Điều này chỉ ra rằng một trong các hoạt động quan trọng của việc tư vấn phòng chống ĐTĐ cho người dân là tư vấn giảm cân cho người thừa cân béo phì. Bác sỹ tư vấn cần tính toán chế độ ăn uống và hoạt động thể lực phù hợp với từng đối tượng thừa cân béo phì để giúp họ về được cân nặng hợp lý.

-Trong nghiên cứu của chúng tôi không thấy có sự khác biệt có ý nghĩa thống kê giữa mắc bệnh ĐTĐ với việc hút thuốc lá $(\mathrm{p}>0,05)$. Điều này có thể do chúng tôi chỉ phỏng vấn lấy số liệu tại thời điểm nghiên cứu, có thể còn một số đối tượng cũng bị ĐTĐ nhưng đã bỏ thuốc lá. Cần có một nghiên cứu cụ thể hơn về mối liên quan giữa hút thuốc lá và bệnh ĐTĐ.

- Trong nghiên cứu của chúng tôi cũng không thấy có sự khác biệt có ý nghĩa thống kê giữa mắc bệnh ĐTĐ với tiền sử gia đình $(\mathrm{p}>0,05)$. Đã có nhiều bằng chứng $\mathrm{y}$ học cho thấy mối liên quan chặt chẽ về yếu tố gia đình trong bệnh ĐTĐ, kết quả nghiên cứu có thể chưa phản ánh đúng thực tế do số người đã được phát hiện mắc bệnh ĐTĐ trong cộng đồng quá thấp (chỉ chiếm tỷ lệ 23,7\%).

\section{KẾT LUẬN}

Tỷ lệ mắc bệnh đái tháo đường và tiền đái tháo đường trong độ tuổi từ 25 tuối trở lên của Vĩnh Phúc năm 2018 cao hơn so với tỷ lệ chung toàn quốc. Tỷ lệ mắc bệnh ĐTĐ là $10,7 \%$; tiền ĐTĐ là 31\%. Có 31,4\% những người được điều tra bị thừa cân béo phì (chỉ số khối cơ thể BMI $\geq 23$ ). Tỷ lệ người bệnh mắc bệnh đái tháo đường trong cộng đồng không được phát hiện lên tới $76,3 \%$. Có mối liên quan có ý nghĩa thống kê giữa bệnh ĐTĐ với giới, tuổi (trên 40), uống nhiều rượu, thừa cân béo phì, tỷ lệ vòng eo/vòng hông cao ở nữ giới $(p<0,05)$.

\section{TÀI LIỆ THAM KHẢO}

1. IDF Diabetes Atlas (2018): Global estimates of diabetes prevalence for 2017 and projections for 2045, Published: February 26, 2018.

2. Bộ Y tế (2018), Quyết định 3280/QĐ$B Y T$ về việc ban hành tài liẹu chuyên môn huớng dẫn chẩn đoán, điều trị bệnh đái tháo đường typ 2, ban hành ngày 09 tháng 9 năm 2011, tr. 4-8.

3. WHO/IASO/IOTF (2000), Redefining Obesity and its Treatment, The AsiaPacific Perspective, Health Communications Australia Pty Ltd, pp. 18-20.

4. Nyamdorj $R$ et al (2008), "BMI compared with central obesity indicators in relation to diabetes and hypertension in Asians", Obesity (Silver Spring), 16(7):1622-35.

5. Cục Thống kê Vĩnh Phúc (2018), Niên giám thống kê Vĩnh Phúc năm 2017, http://niengiamthongke2017.thongkevinh phuc.gov.vn, truy cập ngày 20/3/2019.

6. Hoàng Đức Hạnh, Chu Thị Thu Hà, Bùi Công Đức (2014), "Tỷ lệ hiện mắc bệnh đái tháo đường typ 2 và tiền đái tháo đường của người dân từ 30 - 69 tuổi tại thành phố hà Nội, năm 2014", Tạp chí y hoc dư phòng, tập XXVI, Số 2 (175) 2016, tr: 94. 